\title{
TOMÁS DE MERCADO Y LA TRANSFRETACIÓN GLOBAL DE BIENES Y NORMAS. EMERGENCIA DEL PROBABILISMO Y UNA ÉTICA MERCANTIL DIFERENCIADA*
}

\section{TOMÁS DE MERCADO AND THE GLOBAL TRANSFER OF GOODS AND NORMS. EMERGENCE OF PROBABILISM AND A DIFFERENTI- ATED MERCANTILE ETHICS}

José LUIS EGÍO

MPIeR, Goethe Universität Frankfurt am Main

\section{RESUMEN}

El tema del probabilismo y su emergencia, que durante las últimas décadas parecía un tanto agotado y restringido al nicho de una literatura filosófica muy especializada, se ha revitalizado recientemente gracias a la publicación de las monografías de Stefania Tutino (2017) y Rudolf Schüßler (2019). A modo de complemento a estas investigaciones recientes, en este artículo estudiamos el importante papel -no tenido en cuenta por la historiografía-, que Tomás de Mercado, teólogo formado en las Universidades de México y

\footnotetext{
* Investigador del proyecto La Escuela de Salamanca. Una Colección Digital de Fuentes y un Diccionario de su Lenguaje Jurídico-Político. Proyecto de investigación de la Academia de Ciencias y Literatura de Maguncia (Akademie der Wissenschaften und Literatur Mainz), dentro del marco del programa de proyectos de investigación de larga duración, financiado por la Unión de Academias de Ciencias Alemanas (Union der Akademien der Wissenschaften). Proyecto codesarrollado con la Johann Wolfgang Goethe Universität (Frankfurt am Main) y el Instituto Max Planck para la Historia del Derecho Europeo (Max-Planck-Institut für europäische Rechtsgeschichte, Frankfurt am Main). Directores: Prof. Dr. Thomas Duve, Prof. Dr. Dr. Matthias Lutz-Bachmann.
} 
Salamanca, jugó en la emergencia de esta corriente filosófica, al mismo tiempo, una propuesta de renovación de los métodos practicados en la teología moral de la época. Concentrándonos en los Tratos y contratos de mercaderes y tratantes (1569), analizamos las interesantes y profundas consideraciones metodológicas que, aunque dispersas a lo largo de la obra y no presentadas por el mismo Mercado de forma sistemática, constituyen una de las primeras reflexiones extensas y conscientes sobre la necesidad de adaptar el método teológico-moral a las condiciones de incertidumbre creadas por los descubrimientos ultramarinos. Presentando, por último, los Tratos y contratos como una iniciativa común de la Facultad de Teología de la Universidad de Salamanca, subrayamos la importancia que la Escuela salmantina concedió a la renovación de contenidos y métodos heredados con el fin de que el patrimonio normativo cristiano pudiera sobrevivir, así fuera transformado, en una incipiente economía mercantil caracterizada por una transfretación de bienes y normas cada vez más acelerada y global.

Palabras clave: confesión, contrato, Escuela de Salamanca, ética mercantil, probabilismo, teología moral, Tomás de Mercado.

\section{ABSTRACT}

The research on probabilism and its emergence, which for the last few decades seemed to be exhausted subjects and restricted to the niche of a highly specialized philosophical literature, has recently been revitalized by the publication of the monographs of Stefania Tutino (2017) and Rudolf Schüßler (2019). As a complement to these recent investigations, this article deals with the important role - not taken into account by the old and new historiography - that Tomás de Mercado, a theologian trained at the Universities of Mexico and Salamanca, played in the emergence of probabilism as a philosophical current and as a proposal for the renewal of the methods practiced in the moral theology of the time. Focusing on Mercado's Tratos y contratos de mercaderes y tratantes (1569), this paper analyzes the interesting and profound methodological considerations which, although scattered throughout the work and not presented by Mercado himself in a systematic way, constitute one of the first extensive and conscious reflections on the need to adapt the theological-moral method to the conditions of uncertainty created by the overseas discoveries. Finally, presenting the book Tratos y Contratos as a common initiative of the Faculty of Theology of the University of Salamanca, the article underlines the importance that the Salamanca School gave to the renewal of inherited contents and methods as the only way in which Christian normative heritage could survive -even if transformed-, into an incipient mercantile economy characterized by an increasingly accelerated and global transfetratio of goods and norms.

Keywords: business ethics, confession, contract, moral theology, probabilism, Tomás de Mercado, School of Salamanca. 
I. INTRODUCCIÓN. ¿UN PUNTO CERO PRÁCTICO PARA EL PROBABILISMO? DE LOS COMENTARIOS ERUDITOS DE BARTOLOMÉ DE MEDINA A LA SUMMA TOMISTA AL MANUAL DE CONFESORES DE MERCADERES DE TOMÁS DE MERCADO.

Los grandes expertos en la historia del probabilismo (Delumeau ${ }^{1}$, Schüßler $\left.{ }^{2}, \ldots\right)$ tienden a ubicar su fecha de nacimiento o lo que podríamos considerar como el Big Bang del pensamiento probabilista en la Expositio in primam secundae Angelici Doctoris D. Thomae Aquinatis, obra del teólogo dominico Bartolomé de Medina, publicada originalmente en Salamanca en $1578^{3}$. El tema del probabilismo y su emergencia, que durante las últimas décadas parecía un tanto agotado y restringido al nicho de una literatura muy especializada, se ha revitalizado recientemente gracias a la publicación de dos monografías en las principales editoriales académicas internacionales: la History of probabilism de Stefania Tutino ${ }^{4}$ y The debate on Probable Opinions in the Scholastic Tradition ${ }^{5}$, obra que supone la culminación de la larga trayectoria de investigación dedicada a la historia del probabilismo por parte del profesor Rudolf Schüßler.

Pese a que la consideración de la Expositio de Medina como el hito fundador del probabilismo es una opinión asentada en argumentos sólidos y bastante extendida, no se trata de una posición unánime. Podríamos decir, en términos generales, que la ubicación precisa del punto cero en la historia del probabilismo se debate hoy con la misma intensidad que otras grandes innovaciones, 'descubrimientos' o cambios de paradigma en la historia de la filosofía o del

1 “Étant évident que pour agir il faut sortir du doute, les moralistes avaient jusque-là énoncé les deux règles du "tutiorisme" et du " probabiliorisme". Selon la première il faut, dans une situation douteuse, se déterminer après l'opinion la plus sévère, parce qu'elle est "plus sûre " que l'opinion opposée. La seconde enseigne qu'à défaut de totale certitude il convient de suivre l'opinion la plus probable. La révolution morale, d'origine espagnole, dont Medina et Suarez furent les initiateurs, consista dans l'affirmation qu'en cas de doute on peut suivre toute opinion simplement probable ", Jean Delumeau, L'Aveu et le Pardon. Les difficultés de la confession. XIIIe-XVIIIe siècle (Paris: Fayard, 1992), 133.

2 "Der Probabilismus gehört zu den wenigen moralphilosophischen Doktrinen, für die sich ein bestimmtes Geburtsjahr angeben läßt. Vor Bartolomé de Medina und dem Jahr 1577 scheint niemand die Kernaussage des Probabilismus in voller Allgemeinheit postuliert zu haben. Medina ist sich seiner Pionierleistung bewußt. Er weist stolz darauf hin, daß er sich mit seiner Behauptung in Widerspruch zum bis dahin bestehenden Konsens der Fach-autoritäten setzt“, Rudolf Schüßler, Moral in Zweifel. Band I. Die scholastische Theorie des Entscheidens unter moralischer Unsicherheit (Paderborn: Mentis, 2003), 152.

3 Bartolomé de Medina, Expositio in primam secundae Angelici Doctoris D. Thomae Aquinatis (Salamanca: Matthias Gast, 1578).

4 Stefania Tutino, Uncertainty in post-Reformation Catholicism: a History of Probabilism (Oxford: Oxford University Press, 2018).

5 Rudolf Schüßler, The debate on Probable Opinions in the Scholastic Tradition (Leiden, Boston: Brill, 2019). 
pensamiento. Retomando pasajes y apuntes esbozados hace ya décadas por Delumeau, aunque amortiguando su contundencia, Stefania Tutino dedicó el primer capítulo de su monografía reciente a evaluar la hipótesis según la cual el núcleo de la doctrina probabilista, que permite al agente optar por una opinión o criterio de acción no coincidente con el más seguro para la conciencia, se encontraría ya presente en algunos de los fragmentos dedicados por Martín de Azpilcueta al tema de los escrúpulos de conciencia en su Manual de confessores $y$ penitentes $(1556)^{6}$.

En términos generales éste y otros intentos ${ }^{7}$ por retrotraer el origen del método probabilista de argumentación en la teología moral a obras o autores anteriores a los comentarios de Bartolomé de Medina a la Prima Secundae resultan poco convincentes y pueden ser descalificados si, en lugar de como frase o párrafo suelto, el fragmento clave en el que se supone se encontraría ya el origen del pensamiento probabilista se lee en su marco y contexto propio. Por ejemplo, es cierto, como apunta Tutino, que en un pasaje de su Manual de confessores, Azpilcueta señala que "it is not always necessary to choose the safest alternative, because it is usually sufficient to choose a safe action" 8 . Ahora bien, si leemos esta frase en el marco del orden general de exposición que Azpilcueta sigue en el capítulo XXVII de su Manual, podemos apreciar que el Navarro considera necesario optar siempre por la opción más segura para la conciencia en todos aquellos casos en los que la salvación del alma esté implicada, en particular en asuntos relacionados con la fe y las costumbres. De hecho, justo antes de la frase

6 Martín de Azpilcueta, Manual de confessores y penitentes (Salamanca: Andrea de Portonaris, 1556). Tutino se refiere a pasajes del capítulo 27 del Manual ya presentes en las primeras ediciones de este texto clásico de la literatura de confesión y retomados en la edición latina impresa en Roma en 1584, que es la que Tutino sigue concretamente: "Addo, non semper esse necessarium partem tutiorem eligere, quia satis est quo ad praecepti implementum tutam eligere, ut late in d. cap. Si quis autem a num. 34 probavimus, etiam in his quae ad fidem \& mores pertinent; in aliis enim nec de consilio quis tenetur eligere tutiorem, ut ibidem probatur", Martín de Azpilcueta, Enchiridion, sive Manuale Confessariorum, et Poenitentium (Roma: Giorgio Ferrari, 1584), 1006. "Que no se sigue desto, ser siempre necessario escoger la parte mas segura: porque comunmente basta escoger la segura, como lo prouamos largamente en otra parte: mas solamente se prueua, que ello se ha de hazer enlas cosas que son dudosas, y necessarias a la saluacion del alma, quales son las de la fe, y costumbres". Azpilcueta, Manual de confessores y penitentes (1556), Cap. XXVII, 793.

7 En L'aveu et le pardon, p. 129, Delameau ofrece un ejemplo similar de interpretación en clave probabilista de un pasaje de la Summa theologica de Antonino de Florencia, escrita en 1449 e impresa por primera vez entre 1477 y 1479. Sin entrar a valorar aquí, por razones de espacio, el contenido de este pasaje y la historia de su recepción (en Gonet, De la Font y los principales autores que ofrecieron las primeras perspectivas históricas sobre el probabilismo), cabe mencionar que su interpretación interesada fue denunciada ya por Daniele Concina como una manipulación perversa llevada a cabo por los probabilistas para respaldar sus posiciones filosóficas en una autoridad clásica de la talla de Antonino. Ver Daniele Concina, Della Storia del Probabilismo, e del Rigorismo, Tomo Primo (Venecia: Simone Occhi, 1743), 372.

8 Tutino, Uncertainty in post-Reformation Catholicism: a History of Probabilism, 36. 
a la que Tutino apunta de una forma un tanto arbitraria y deliberadamente confusa, Azpilcueta está afirmando con contundencia: "que la consciencia dudosa especial sobre algo, si es o no pecado mortal, obliga a escoger la parte mas segura so pena de pecado"9.

En realidad, el tipo de escrúpulos al que Azpilcueta se está refiriendo cuando concede parcialmente el que se pueda seguir una vía de acción distinta a la más segura para la conciencia -tutior-, tiene que ver con dudas suscitadas por asuntos relativamente secundarios y ligados a preceptos ceremoniales. Los casos en los que está pensando cuando realiza esta concesión son, por ejemplo, las dudas que se plantean a propósito de qué tipo de actividades no físicas o manuales, pero que implican un cierto esfuerzo, se pueden realizar en los días de fiesta sin violar el precepto de santificar las fiestas. Se trata de la materia típica en la que, en ausencia de una posición claramente más segura y susceptible de ser aplicada a la gran diversidad de casos que podían plantearse al respecto, el actuar conforme a un criterio probable -así no fuera claramente el más seguro- podía ser considerado suficiente para evitar pecar por violación del precepto.

Más que en el tratamiento de los escrúpulos de conciencia, podemos encontrar materiales interesantes para entender la prehistoria del probabilismo en otras de las temáticas abordadas por la literatura de confesores en la Primera Modernidad. La Suma de tratos y contratos de mercaderes y tratantes escrita por Tomás de Mercado en 1569 y dedicada a una multitud de actividades económicas (productivas, comerciales y bancarias) es, por ejemplo, una obra de gran interés para entender lo que podríamos considerar como una prehistoria del probabilismo antes de Bartolomé de Medina, es decir, el contexto social y

9 "XVI. Que la consciencia dudosa especial sobre algo, si es o no pecado mortal, obliga a escoger la parte mas segura so pena de pecado. M. porque otramente se pone a peligro de pecar mortalmente, como lo diximos en otra parte 11 In. d. c. Si quis autem. n. 42., dando exemplo del que duda si es pecado mortal, o no tener dos beneficios, aunque sean simples: ca si los toma dudando, peca mortalmente $\mathrm{m} \mathrm{m}$ Thom. in quoli. 8. ar. 13. Y se puede poner del que duda de algun pecado, si es mortal, o no. Ca peca mortalmente, sino lo confiessa. Lo qual procede, aun quando la consciencia no es del todo dudosa, por parecerle más verdadera la vna parte, que la otra si en ninguna assegura, como lo prouamos largo allí. Diximos (especial) porque la general, no basta para esto: como lo diximos alli, del letrado que duda en general, si es licito aconsejar el dia de fiesta. Pero no duda, antes tiene por cierto, que le es licito al que lo haze. Lo qual mesmo se podria dezir de la consciencia cierta general, y de su contraria especial. No se dize empero la consciencia dudosa, porque algunos escrupulos sienta en si contra lo que determina de hazer, si cree, o tiene opinion prouable, que es bueno, por ley, authoridad, o razon sufficiente, para tenerlo assi, a juyzio de varon de sciencia, y consciencia, puesto que la mayor parte de los doctores tengan lo contrario. Que no se sigue desto, ser siempre necessario escoger la parte mas segura: porque comunmente basta escoger la segura, como lo prouamos largamente en otra parte: mas solamente se prueua, que ello se ha de hazer enlas cosas que son dudosas, y necessarias a la saluacion del alma, quales son las de la fe, y costumbres". Azpilcueta, Manual de confessores y penitentes (1556), Cap. XXVII, 792-793. 
económico en el que emergió la metodología para discernir entre varios argumentos probables que impregnará la literatura teológico-moral desde los compases finales del siglo XVI hasta finales del siglo XVII.

Al contrario que otros escolásticos ibéricos, el papel que Tomás de Mercado habría podido jugar en la emergencia del probabilismo moderno ha pasado casi totalmente desapercibido para los historiadores de la filosofía, el derecho y la teología moral hasta el presente. De hecho, los únicos que, a nuestro conocimiento, parecen haber reparado en la importancia del dominico Mercado para esta temática son José Ignacio Saranyana y Carmen Alejos Grau quien, en su voluminosa y erudita Teología en América Latina (2005), consideraron que, aunque Bartolomé de Medina habría sido el primer exponente, propiamente dicho, del probabilismo, el principio sobre el cual fundó su sistema moral era ya conocido y había sido recomendado a los confesores previamente por Tomás de Mercado. Con esta afirmación, Saranyana y Alejos rebajaban, por tanto, la contribución de Medina al nacimiento de la filosofía probabilista a su formulación técnica ${ }^{10}$. Se trata, en todo caso, de un apunte suelto en una obra enciclopédica cuyos autores, al proponerse condensar, precisamente, cinco siglos de historia de las ideas teológicas en América Latina, no desarrollaron por extenso. A la hora de escribir este artículo, nos pareció que merecía la pena retomar, en todo caso, esta interesante pista de investigación y verificar con mayor detenimiento el juicio que Saranyana y Alejos lanzaron en 2005, pero sin aportar el debido fundamento o necesario respaldo textual. La transcendencia para la historia de la filosofía y de las normatividades de la hipótesis lanzada por ambos investigadores -a saber que no sería en un comentario latino, erudito y universitario, a la Summa tomista, sino en un tratado en castellano sobre las materias prácticas relacionadas con tratos y contratos de mercaderes donde cabría ubicar el punto cero de la metodología probabilista, sin duda alguna la innovación doctrinal más importante para la historia de la filosofía moral en la Primera Modernidad- merece, a nuestro juicio, una evaluación detenida y una verificación de la misma con el debido respaldo textual. Con este objetivo, en las páginas siguientes analizaremos los principales fragmentos de la Suma de tratos y contratos (1569) en los que Tomás de Mercado recurre a opiniones probables para solucionar ciertos casos problemáticos o dudas. Nos fijaremos especialmente en las interesantes y profundas consideraciones metodológicas que, aunque dispersas a lo largo de la obra y no presentadas por el mismo Mercado de forma sistemática, constituyen una de las primeras reflexiones

10 José Ignacio Saranyana dir., Carmen José Alejos-Grau coord., Teología en América Latina. Volumen II/I. Escolástica barroca, Ilustración y preparación de la Independencia (1665-1810) (Madrid-Frankfurt: Iberoamericana-Vervuert, 2005), 186. 
extensas y conscientes sobre la necesidad de adaptar el método teológico-moral a las condiciones de incertidumbre creadas por los descubrimientos ultramarinos. La Suma de tratos y contratos de Tomás de Mercado podría verse, en este sentido, como una de las primeras respuestas filosófico-morales a la emergencia de una red global en la que no sólo bienes, sino también prácticas y normas, comienzan a ser objeto de una transfretación ${ }^{11}$ que, por primera vez en la historia, alcanza dimensiones planetarias y que, con un volumen cada vez mayor, mantendrá su crecimiento exponencial hasta nuestros días.

\section{REFLEXIONES DE UN TEÓLOGO MORAL BICONTINENTAL. TRANSFRETACIÓN TRANSATLÁNTICA DE BIENES, NORMAS Y PRÁCTICAS Y NECESIDAD DE ADAPTACIÓN DE LA DISCIPLINA}

Nacido en Sevilla en la década de 1520, Tomás de Mercado fue llevado a México por sus padres cuando aún era un niño. Según consta en diversos documentos conservados en el Archivo de Protocolos de Sevilla y el Archivo General de Indias, diversos integrantes de su familia -repartida entre la vieja y la Nueva España- se ocupaban de actividades comerciales y bancarias como la compra-venta de bienes, el préstamo de dinero, la administración de compañías mercantes, el cambio de divisas o el envío de plata desde las Indias a Sevilla ${ }^{12}$. No por casualidad, se trata de los tipos de prácticas mercantiles, societarias y

11 No podemos entrar aquí en una explicación más detallada sobre el concepto de transfretación como alternativa teórica al manido y, en ocasiones, acríticamente empleado concepto de circulación, a la vez que como complemento al concepto de traducción cultural desarrollado por Peter Burke, "Cultures of Translation in Early Modern Europe", en Cultural translation in Early Modern Europe, ed. por Peter Burke, Ronnie Po-Chia Hsia (Cambridge, Cambridge University Press, 2007), 7-38. El concepto de traducción cultural es una pieza clave en las propuestas renovadoras de los estudios histórico-jurídicos desarrolladas por Thomas Duve y Lena Foljanty. Sirva este apunte como esbozo de una contribución monográfica posterior. Sobre los problemas derivados de un uso acrítico de los conceptos de circulación y transplante: Thomas Duve, "European Legal History - Concepts, Methods, Challenges", en Entanglements in Legal History: Conceptual Approaches, ed. por Thomas Duve (Frankfurt am Main, MPIeR, 2014), 29-66. Lena Foljanty, "Legal Transfers as Processes of Cultural Translation: On the Consequences of a Metaphor", Max Planck Institute for European Legal History Research Paper Series 9 (2015): 1-18. He estudiado diversos casos de traducción cultural de normas y prácticas entre Europa y México (Nueva España) en la Primera Edad Moderna en: José Luis Egío García, "From Castilian to Nahuatl, or from Nahuatl to Castilian? Reflections and Doubts about Legal Translation in the Writings of Judge Alonso de Zorita (1512-1585?)", Rechtsgeschichte - Legal History $\operatorname{Rg} 24$ (2016): 122-153; José Luis Egío García, "Pragmatic or Heretic? Editing Catechisms in Mexico in the Age of Discoveries and Reformation (1539-1547)", en, Knowledge of the Pragmatici. Legal and Moral Theological Literature and the Formation of Early Modern Ibero-America, ed. por Thomas Duve, Otto Danwerth (Leiden, Brill, 2020), 235-274.

12 Antonio-Miguel Bernal, “Tomás de Mercado y las 'negociaciones' con las Indias”, en Tomás de Mercado, Tratos y contratos de mercaderes y tratantes. Edición facsimilar (Salamanca, Universidad de Salamanca: 2015), 47-49. 
crediticias que, algunos años más tarde, el Tomás de Mercado ya adulto y convertido en fraile dominico analizará moralmente en su Suma.

Criado en este ambiente de tratantes, Tomás de Mercado ingresará en la orden dominica en 1552 y comenzará poco después sus estudios de Artes y Teología en la recién creada Universidad de México (1555). Es importante tomar en consideración que Mercado estudia en un período en el que los dominicos Pedro de Pravia ${ }^{13}$ y Bartolomé de Ledesma y el agustino Alonso de la Vera Cruz, todos ellos discípulos de Francisco de Vitoria en la Universidad de Salamanca, ocupan las principales cátedras de teología de la Universidad de México. Desde principios de la década de 1560, encontramos a Mercado de regresó en España y residiendo entre Sevilla, donde estaba arraigada una parte de su familia, y el famoso convento de San Esteban en Salamanca. Dado que en México había recibido una formación teológica preliminar, no completada con el grado de maestro ni de doctor-Mercado firma la primera edición de la Suma de tratos y contratos (1569) como "Padre Presentado" 14 y se identifica como "Maestro en sancta Theologia" sólo a partir de la segunda edición de la obra, publicada en $1571^{15}$-, Mercado debió ser apoyado por sus superiores en la orden dominica para que profundizara en sus estudios teológicos. Lo encontramos matriculado en la Facultad de Teología de la Universidad de Salamanca, de forma un tanto intermitente, entre 1563 y $1569^{16}$, período en el que los miembros más destacados del cuerpo docente son Pedro de Sotomayor, Mancio de Corpus Christi, Juan de la Peña o Luis de León, es decir, la generación inmediatamente precedente a Bartolomé de Medina ${ }^{17}$.

El manual de confesores de mercaderes y tratantes escrito por Tomás de Mercado refleja con claridad la transfretación del joven y despierto dominico entre ambientes tan distintos como los de la emergente Ciudad de México, la austera y docta Salamanca y una Sevilla en ebullición. Rebosante de una

13 Alberto Carrillo Cazares, "Un tratado perdido de fray Pedro de Pravia", Anuario de Historia de la Iglesia 16 (2007): 355-360.

14 Tomás de Mercado, Tratos y contratos de mercaderes y tratantes discididos y determinados, por el Padre Presentado Fray Thomas de Mercado, de la orden de los Predicadores (Salamanca: Matthias Gast, 1569).

15 Tomás de Mercado, Summa de tratos, y contratos. Compuesta por el muy Reverendo Padre Fray Thomas de Mercado de la Orden de los Predicadores, Maestro en sancta Theologia. Dividida en seis libros (Sevilla: Hernando Díaz, 1571).

16 En los libros de matrículas, Mercado figura inscrito como estudiante durante los cursos académicos 1563-64, 1566-67 y 1568-69, Bernal, “Tomás de Mercado y las 'negociaciones' con las Indias", 74.

17 Una información detallada y recientemente actualizada sobre todos los docentes que ocuparon cátedras en la Facultad de Teología de la Universidad de Salamanca entre 1560 y 1641 en la reciente monografía de José Barrientos García, La Facultad de Teología de la Universidad de Salamanca a través de los libros de visitas a cátedras (1560-1641) (Madrid, Porto: Sindéresis, 2018). 
experiencia vital y práctica que no encontramos en las obras eruditas concebidas para un público lector específicamente universitario y clerical, el manual es, al mismo tiempo, una obra en la que abundan especulaciones metodológicas de alto vuelo intelectual. A diferencia de los autores a los que, con mayor o menor razón, se ha solido considerar como precedentes del probabilismo moderno -los ya citados Antonino, Azpilcueta, etc.- el recurso de Mercado a la argumentación probable no es esporádico ni se da de forma aislada. Al contrario, Mercado no sólo recurre con frecuencia a argumentos probables para la resolución de casos de conciencia problemáticos, sino que enfoca la probabilidad como la clave de bóveda de las recomendaciones metodológicas que dirige a sus colegas del gremio de los confesores y otros teólogos prácticos. Consciente de que la mayoría de estos clérigos eran hombres de vida retirada y que conocían poco la práctica corriente de los negocios y las grandes innovaciones que, de forma incesante, se habían venido sucediendo en los ámbitos de los tratos y contratos de mercaderes, el 'mundano' y 'transfertado' Mercado se propone como misión orientar a sus colegas en el complejo laberinto de acciones, normas y probabilidades en el que se habían convertido las esferas de los contratos, préstamos y cambios desde el Tardo Medievo ${ }^{18}$. En el contexto hispánico resulta indudable que tanto el 'descubrimiento' del Nuevo Mundo, motor de una rápida creación de redes comerciales a escala planetaria, como la integración de Castilla y Aragón al complejo Imperio pan-Europeo de los Habsburgo, añadió aún más complejidad a una reflexión moral sobre las prácticas comerciales y crediticias que ya era intensísima en Europa desde varios siglos atrás ${ }^{19}$.

18 Sobre la relación intrínseca entre el desarrollo económico y social, la aparición continua de opiniones probables controvertidas y la consiguiente evolución de la teología moral desde el período tardo-medieval, Schüßler, The Debate on Probable Opinions in the Scholastic Tradition, 12.

19 Un panorama general y multidisciplinar sobre la reflexión medieval en torno al crédito y usura en distintas regiones de Europa en Diego Quaglioni, Giacomo Todeschini y Gian Maria Varanini, eds., Credito e usura fra teología, diritto e amministrazione (Roma: École Française de Rome, 2005). 


\section{RESCATANDO A LA TEOLOGÍA PARA LA VIDA. ANTI- ACADEMICISMO Y PRAGMATISMO EN LOS TRATOS Y CONTRATOS DE TOMÁS DE MERCADO}

Como hemos señalado, la Suma ${ }^{20}$ de Mercado no es un libro académico convencional o destinado al público letrado y universitario de su tiempo. Escrito en lengua vernácula y sin apenas referencias a autoridades no presenta la complejidad de los comentarios teológico-morales a la Summa tomista que en esta misma época comenzaban a proliferar ${ }^{21}$ y ni siquiera el ropaje erudito del que se revestían manuales de confesión como los que Martín de Azpilcueta ${ }^{22} \mathrm{o}$ Tomás de Chaves ${ }^{23}$-sintetizando este último el contenido de algunos de los cursos dedicados por Vitoria al $I V$ de las Sentencias de Pedro Lombardo- habían publicado pocos años antes. Mercado pretende ser claro y conciso de forma deliberada. Por ello, desde el comienzo de la obra, afronta toda clase de cuestiones -sin rehuir las más complejas- en la forma más breve y simple posible.

Mercado marca distancias, especialmente, con los diversos comentarios académicos que versaban sobre las Quaestiones dedicadas por Tomás de Aquino a los contratos, cambios y usura en la Summa theologiae (IIa-IIae, qq. 77-78). Apuntando, en un primer momento, explícitamente a los mercaderes -más allá del clero letrado- y a esas "muchas personas que, sin lumbre de leyes divinas, ni humanas se meten atrevidamente en muy espesas tinieblas de contratos" ${ }^{\prime 24}$ como el público al que, preferencialmente, ofrecía su obra, quedan justificados en adelante los criterios metodológicos empleados para redactar la Summa en un estilo llano y antiacadémico. Mercado subraya, especialmente que, en su intento por elaborar una obra popular y útil, había evitado deliberadamente el apoyarse en las autoridades clásicas que las obras académicas sobre moral y comercio citaban y analizaban por extenso ${ }^{25}$. Asimismo, y so pena de pasar por ignorante,

20 Empleamos el término Suma para referirnos tanto a la primera (1569) como a la segunda edición de la obra (1571), aunque sólo ésta segunda recoja en su título la palabra Suma. En realidad, aunque la reedición sevillana del tratado de Mercado incorpora muchos materiales nuevos, no difiere de la primera edición salmantina en su condición de Suma "en orden y estilo claro de muchas decisiones de casos tocantes a mercaderes", Mercado, Tratos y contratos de mercaderes y tratantes, "Epistola nuncupatoria", [s.p.].

21 Por iniciativa de Vitoria y Soto y a partir de las clases de ambos en Salamanca y del influyente De iustitia et iure (Salamanca: Andrea de Portonaris, 1553). 1556).

22 Martín de Azpilcueta, Manual de confessores y penitentes (Salamanca: Andrea de Portonaris,

23 Tomás de Chaves, Francisco de Vitoria, Confessionario (Santiago: [s.n.], 1562); Tomás de Chaves, Francisco de Vitoria, Summa Sacramentorum (Valladolid: Sebastián Martínez, 1561).

24 Mercado, Tratos y contratos de mercaderes y tratantes, "Prologo", [s.p.].

25 Mercado, Tratos y contratos de mercaderes y tratantes, "Y tomado este destino, mi cuydado principal fue tener siempre ante los ojos el talento, y condicion de la gente a quien mostraua, diziendo 
advertía a sus lectores escolásticos que no encontrarían en su obra el típico ejercicio de defensa de argumentos pro y contra en torno a una cierta sentencia o proposición, sino que muchos de los argumentos que hubieran podido ser mencionados y evaluados a la hora de abordar ciertas cuestiones o casos los había dejado en el tintero para no espantar de antemano con un volumen pesado y farragoso al público general al que quería alcanzar con su obra.

El pragmatismo de Mercado se conjuga con una conciencia histórica clara sobre la excepcionalidad del período en que los hombres y mujeres de su generación estaban viviendo. El dominico sabía, por supuesto, que Sevilla, como otras muchas ciudades costeras y ribereñas, había sido siempre un destino frecuentado por viajeros y comerciantes. Sin embargo, desde su perspectiva, el "descubrimiento" de las Indias Occidentales estaba implicando una transformación inédita de la estructura social y económica de la ciudad:

Pero de sesenta años a esta parte, que se descubrieron las Indias occidentales: se le recrescio para ello una gran comodidad y una ocasion tan oportuna, para adquirir grandes riquezas: que combido y atraxo a algunos de los principales a ser mercaderes, viendo en ello pujantissima ganancia. Porque se avian de proveer de aqui muchas provincias. La ysla Española, Cuba, Honduras, Campeche, nueva España, Guatemala, Carthagena, tierra firme, con toda la grandeza del Peru $[\ldots]_{26}$.

En la obra de Mercado encontramos una honda preocupación acerca de la rápida evolución que, en paralelo a los descubrimientos geográficos, estaba teniendo lugar en la esfera de las prácticas comerciales. Muchas de ellas le parecen al dominico tan fuera de todo control moral y religioso como lo estaban aquellas mismas Indias de las que, continuamente, llegaban noticias sobre mil desmanes y abusos. Mercado es consciente, por ejemplo, de que un "trato tan universal", que conecta por primera vez en la historia y hace interdependientes a distantes regiones situadas en cuatro continentes (Flandes, Florencia, Cabo

\footnotetext{
en cada punto y contrato, solamente lo que bastasse, no todo lo que para ornato y hermosura de la obra se pudiera decir [...] Mas considere que vestida de todas sus ropas, que son la efficacia de razones, en que estriba, y la authoridad de los doctores, que la affirman abultaria, tanto con su corpulencia, que no cabria la materia de toda esta obra en dos grandes tomos. Lo qual fuera causa que por el titulo de perfecta, y galana, que cobrara, perdiera el de prouehosa y se frustrara nuestro intento que es mostrar a muchas personas, que sin lumbre de leyes diuinas, ni humanas se meten atreuidamente en muy espesas tinieblas de contratos [...]Para esto es muy justo abreuiarla, estenderla, atauiarla, o descomponerla conforme a su ingenio. Por lo qual jusgue por acertado hazer la obra falta, temiendo y creo que con bastante causa que a salir perfecta y vistosa le faltara con toda su beldad (como dizen) la ventura que es mejor. Porque no alcançara el bien que se pretende, ni fuera sabrosa su lection al negociante", "Prologo", [s.p.].

26 Mercado, Tratos y contratos de mercaderes y tratantes, ff. $1 \mathrm{v}-2 \mathrm{r}$.
} 
Verde, Lisboa, Burgos, Lyon, Calcuta, Santo Domingo, México,...) había hecho que el cambio, "que accidental o accessoriamente antes se hazia, entre solos mercaderes, començo a ser particular, y principal negociacion de algunos" ${ }^{\text {"27 }}$.

La interconexión entre una multitud de ciudades que comercian a escala planetaria implica también, como avezadamente indica Mercado, una innovación sin precedentes en la práctica de tratos y contratos. Por otro lado, y al igual que los bienes, una vez concebidas en Florencia, Calcuta o Cabo Verde, estas nuevas prácticas mercantiles comienzan a circular globalmente y a dejar atrás a las normatividades y prácticas consuetudinarias que eran propias de cada puerto o ciudad. El nuevo panorama mercantil es tan enredado y complejo que, como Mercado indica con un cierto dramatismo, la mayoría de los confesores, desprovistos del conocimiento y la experiencia práctica necesarias para pronunciarse sobre temáticas que los desbordan, se quedan totalmente al margen de los negocios que llevan a cabo los comerciantes. Ni pueden juzgar las acciones de este tipo de penitentes in foro conscientiae, ni tampoco aconsejarlos sobre determinados métodos y procedimientos que les permitan proseguir sus tratos sin poner en peligro la salud de sus almas. Mercado se rebela en cierto modo ante la desconexión creciente entre la teología escolástica y erudita que se enseña dentro de los muros de universidades y colegios y un mundo de la vida que bulle de novedades. Estas innovaciones resultan inasibles para la mayoría de los teólogos morales en la medida en que, por desconocer y despreciar, en cierto modo, la "praxis" de los "negocios" que ocupan a los hombres "vulgares", no hallan el modo de conectar y aplicar la sabiduría "theorica" que han aprendido durante su formación académica a los casos y

27 "Los de Burgos tienen aqui sus factores, que o cargan en su nombre, o aseguran a los cargadores, o resciben, o venden, lo que de Flandres les traen. Los de Italia tambien han menester a los de aqui: para los mesmos effectos: de modo que qualquier mercader caudaloso trata el dia de oy en todas las partes del mundo, $\mathrm{y}$ tiene personas que en todas ellas les correspondan den credito y fee a sus letras, y las paguen, porque han menester dineros en todas ellas. En Cabouerde para los negros, en Flandes para la merceria, en Florencia para las raxas: en Toledo y Segouia para los paños: en Lisboa para las cosas de Calicut. Los de Florencia y los de Burgos tienen necessidad dellos aqui, o para seguros que hizieron, y se perdieron, o de cobranças de la ropa que embiaron, o cambios que en otras partes tomaron remitidos aqui. Todos penden vnos de otros, y todo quasi tira, y tiene respecto el dia de oy a las Indias, Sancto Domingo, Sancta Martha, tierra firme, y Mexico, como a partes do va todo lo mas gruesso de ropa, y do viene toda la riqueza del mundo. De modo que qualquiera destos de gradas (con quien particularmente hablamos) tiene necessidad de tener dineros en todas partes, o para comprar, o pagar, o cobrar, porque en todas deuen, y les deuen. Y este ser su trato tan vniuersal, fue causa principal vuiesse cambiadores [...] De modo que lo que accidental o accessoriamente antes se hazia, entre solos mercaderes, començo a ser particular, y principal negociacion de algunos", Mercado, Tratos y contratos de mercaderes y tratantes, "Opusculo de cambios", Cap. III, "De la pratica en los cambios destos tiempos", ff. 85v-86r. 
dudas concretos que deberían poder resolver en su calidad de confesores o consultores de mercaderes y potentados:

En este opusculo me parescio quasi necessario escreuir con la Theorica destos negocios, juntamente la practica y hecho dellos, porque la saben los vulgares, y acaesce ignorarla alomenos no entendella cumplidamente los muy doctos [...] Y como el derecho en estos contratos se funda en el hecho, no raro dan algunos padres Theologos mill leguas del blanco, y atinan tan mal, que los mesmos mercaderes los jusgan por ciegos. A cuya causa me parescio conuenible, gastar algun pedaço desta obrilla, en dezir que traça, medios, y arte tienen oy los cambiadores en negociar. Porque sabido, sera facil jusgar, $\mathrm{y}$ ver quanto se suele negociando acertar, $\mathrm{o}$ errar. $\mathrm{Y}$ no deue a los cambiadores serles tedio leer, lo que ya se saben, porque quise hazer este seruicio a los padres confessores, que con su gran recogimiento, no pueden alcançar el praxis de negocios tan enmarañados, que los mesmos tratantes se hallan, no pocas vezes cortos y atajados sin saber darse mano, ni salir de do entraron ${ }^{28}$.

\section{EMERGENCIA DEL PROBABILISMO Y NECESIDAD DE ADAPTACIÓN DE LA PRÁCTICA DE LA CONFESIÓN A UN CONTEXTO PRÁCTICO CARGADO DE COMPLEJIDAD E INCERTEZA.}

En este mundo de prácticas cambiantes, Mercado -y por extensión, los destacados teólogos salmantinos que recomiendan su obra en las cartas prefatorias de la edición de 1569- entrevé el riesgo de una clara ruptura entre el comercio y la normatividad religiosa y moral ${ }^{29}$. En este sentido, Mercado parece decir a sus colegas dominicos y agustinos (las dos órdenes impulsaron la obra, contando la misma con el beneplácito de destacados miembros de ambas): si queremos evitar una escisión total entre acciones y normas, entre teoría y práctica, no sólo es necesario ahondar en las estrategias de simplificación y condensación de las exposiciones teóricas que caracterizan la producción teológico-moral escolástica, sino también abandonar el "recogimiento" excesivo en el que viven muchos confesores y que, pese a deberse a motivaciones pías y dignas de encomio, los hace incapaces para el juicio práctico. Eso implica para Mercado, en primer lugar, una transformación del método escolástico de investigación, para que éste tienda a un mayor equilibrio

28 Ibid., ff. $84 \mathrm{v}-85 \mathrm{r}$.

29 Por ejemplo, el dominico Diego Rodríguez, titular de la cátedra de Santo Tomás en la Facultad de Teología en este período, recomienda la lectura de los Tratos y contratos de Mercado como una obra cuyas doctrinas resultan "muy necessarias para remediar la quiebra de la justicia, que anda tan desterrada en nuestros infelices tiempos, en todo genero de negociacion", Ibid., [s.p.]. 
entre el peso concedido a la razón y a la autoridad, en lugar de hacer a la razón $-\mathrm{y}$, por extensión, a la praxis o lógicas propias de las esferas que la teología moral pretende normar- un instrumento meramente subsidiario y exegético de un saber cuyos principios están ya dados ${ }^{30}$.

También como respuesta a la complejidad creciente que mencionamos, encontramos en la obra de Mercado una exhortación contundente a que la práctica de la confesión se transforme o se adapte, al menos, al alto grado de incertidumbre que caracteriza la profesión de mercaderes, cambistas y banqueros. Para Mercado, dado que la complejidad e incerteza que prevalecía y seguía, de hecho, aumentando- en la esfera de los tratos y contratos hacía muy difícil que el confesor pudiera determinar el curso de acción más seguro -tutiorpara su penitente o el argumento que con mayor probabilidad se ajustaba a su caso - probabilior-, la confesión y consulta teológica sobre este tipo de asuntos debía convertirse en un intercambio de opiniones y alternativas (tan sólo) probables entre confesor y penitente.

Usualmente peor informado acerca de las prácticas mercantiles que el mismo penitente, la autoridad incontestable del confesor parece disolverse poco a poco. Se conserva, obviamente, de iure, pero dada esta creciente y casi irremediable brecha de conocimiento, Mercado recomienda a los confesores que trabajan específicamente con el gremio de los tratantes el "no ser tan amigos de sus propios conceptos", evitando imponer su propio criterio estrecho al penitente,

[...] sino quiere ser reglado, ni seguilla [la regla dada por el confesor]: y la que sige es probable, y tiene sus razones, fundamentos y autores: basta a consejarle, lo que tiene por mas cierto, o mas le agrada, pero si al penitente le desagrada: y lo que haze, se puede hazer y lo apruevan muchos autores aprobados: gran tochedad y arrogancia seria: porque el lo repruebe, no absolvelle: sino desiste dello: aviendo en un contracto por una parte y por otra opiniones buenas entre doctos: cada uno es libre para seguir la que escogiere:

30 En el lado opuesto encontramos a Melchor Cano, cuyo tratado metodológico De locis theologicis había sistematizado poco antes un método de argumentación teológica en el que la teología se presenta -en oposición al resto de disciplinas- como un saber "in qua non tam rationis in disputando, quam auctoritatis momenta quaerenda sunt. Et enim locum ab auctoritate adeò sibi proprium vendicavit, ut rationes vel tamquam hospites \& peregrinas excipiat, vel in suum etiam obsequium asciscat, quasi longe repetitas", (Salamanca: Matthias Gast, 1563), p. 3. "Pero así como en las demás ciencias la Razón ocupa el primer lugar y el último la Autoridad, la teología, en cambio, es la única ciencia en la que se ha de buscar en la discusión no tanto la importancia de la Razón cuanto la de la Autoridad. Pues de tal manera ha reivindicado para sí el lugar a partir de la Autoridad que recoge las razones como extrañas y peregrinas, o las toma según su conveniencia, como venidas de lejos", Melchor Cano, Los lugares teológicos, trad. cast. de Juan Belda Plans (Madrid: Biblioteca de Autores Cristianos, 2006), 1-2. 
lo mesmo en substancia entiendo, quando fuera de confesión se propone al theologo un negocio, que si por entrambas partes ay opiniones: y lo uno, y lo otro se puede hazer y seguir sin peligro (dado que el aya escogido una dellas por mas probable) no deve atar con ella al que pregunta, sino dezirle de plano su parecer: avisandole: que haziendo lo contrario no es peccado: porque ay muchos doctores que lo tienen por licito: tengo este consejo por muy importante en negocios de mercaderes que comúnmente son de interes ${ }^{31}$.

Esta posición, sin ser totalmente probabilista, puesto que no admite aún que el agente-penitente siga una opinión meramente probable privilegiándola frente a otra claramente más probable, debe ser considerada, sin embargo, como un importante paso adelante en relación con los desarrollos metodológicos que llevará a cabo Bartolomé de Medina una década más tarde. En efecto, Mercado está proponiendo al confesor que incluso aunque la alternativa de acción deseada por su penitente o asesorado no sea la que él mismo tiene por más cierta, no lo obligue a seguir su opinión si el mercader puede defender la suya con algunos buenos argumentos que tengan, además, un cierto respaldo en autores reconocidos como autoridades. Nótese como Mercado, pese a reducir al máximo las citas a los "doctores", los considera aún ineludibles a la hora de respaldar argumentos y opiniones, de ahí que consideremos su propuesta como una adaptación o transformación del método escolástico de resolución de casos teológico-morales y, en ningún caso, un abandono del mismo.

De acuerdo con la reciente reconstrucción de la historia del probabilismo que encontramos en la obra de Rudolf Schüßler, The debate on Probable Opinions in the Scholastic Tradition, una posición como la de Mercado habría tenido algunos precedentes en la teología moral del tardo-medievo. Schüßler ha apuntado, por ejemplo, a Antonino de Florencia o Konrad Summenhart como autoridades teológicas que contribuyeron a mitigar la autoridad de los confesores en este período. Antonino, por ejemplo, habría considerado que "a confessor who doubted the moral legitimacy of a action ought (debet) to absolve a penitent who followed a probable opinion of a doctor" 32 . En nuestra opinión, Mercado está un paso más adelante que Antonino: en los casos que tiene en mente resulta indiferente que el confesor tenga o no dudas; de hecho, lo único

31 Mercado, Tratos y contratos de mercaderes y tratantes, f. 15r. El gran historiador de la teología española, Melquiades Andrés, ya había llamado la atención sobre este pasaje como un reconocimiento por parte de confesores y teólogos de "la dificultad de comprender los fenómenos económicos y las leyes del mercado", Melquiades Andrés, La teología española en el siglo XVI (Madrid: Biblioteca de Autores Cristianos, 1977), vol. II, 464.

32 Schüßler, The debate on Probable Opinions in the Scholastic Tradition, 459. 
que resulta relevante es que la posición defendida por el penitente pueda ser argumentada probabiliter.

La posición de Mercado resulta en cambio mucho más cercana a la que Schüßler ha reseñado en el teólogo y canonista alemán Konrad Summenhart, quien a finales del siglo XV habría exhortado a los "ordinary confessors to absolve agents who followed an opinion that was controversial among scholars, even if the confessor held the opposite opinion on probable grounds" ${ }^{\prime 3}$.

Pese a contar con algunos precedentes relativamente recientes, posiciones como las defendidas por Mercado no gozaban ni mucho menos de unanimidad durante el siglo XVI. Al contrario, resultan marginales y casi excepcionales. Schüßler ha señalado, por ejemplo, como Azpilcueta -la gran lumbrera de la teología moral en este período-, reevaluando las palabras de Antonino arriba citadas en su Manual de confessores, no quiso aventurarse a pronunciarse "about the question whether a confessor had to absolve against his own opinion or only when in doubt" ${ }^{\prime 34}$.

Si comparamos también las posiciones de Mercado sobre la autoridad de teólogos y confesores con las de Vitoria, resulta también claro que el sevillano está bastante alejado del que la historiografía tiene por fundador del método teológico salmantino. Mercado comparte con Vitoria, por supuesto, la convicción de que todo actor confrontado con un caso de conciencia dudoso tiene la obligación de consultar a un teólogo docto y experto en la materia. Mercado no solo comparte, sino que, de hecho, radicaliza, la exhortación de Vitoria, haciendo del confesor experto una sombra omnipresente en la vida del mercader. Le recuerda a éste que, dado el amplio número de casos con los que tendría que lidiar a lo largo de su vita activa y su gran diversidad y complejidad, no le bastarían para actuar con seguridad de conciencia sus criterios personales, estudios recibidos o la literatura que pudiera adquirir. Por ello, para esta clase de profesionales, como sostiene Mercado, el apoyarse en un confesor experimentado no era simplemente una recomendación, sino una auténtica "obligación y pura necessidad" 35 . Podríamos hablar incluso de este precepto como uno de los elementos centrales y distintivos de la Berufsethik particular

33 Ibid., 459.

34 Ibid., 460.

35 "Vltimamente, deue tener vn confessor senalado hombre de sciencia y consciencia, aun que a la verdad, no es tan consejo esto en el mercader: quanto obligacion y pura necessidad, ni ay instruction, ni documentos, ni libros que tanto ayan menester, porque ningunas reglas se pueden dar tan bastantes que se responda en ellas a todos los casos ocurrentes, antes aun en estas pocas, que se escriuen, se dexa la aplicación dellas al juyzio de vn hombre experto en los negocios que entienda la platica", Mercado, Tratos y contratos de mercaderes, f. 14r. 
que Mercado parece perfilar para el gremio de los mercaderes en su Suma de tratos y contratos, asunto sobre el que volveremos más adelante.

Partiendo de este acuerdo inicial, lo que distingue a Vitoria y Mercado es la libertad concedida por este último al agente-penitente, habilitado para seguir su propio criterio de acción en la medida en que lo habilitaran algunas buenas razones, argumentos o autores. Vitoria, quien, tres décadas antes, había trabajado en un perspectiva mucho más estrecha y clásica, había supuesto siempre al confesor mejor informado que su penitente, razón que le lleva, por ejemplo, a hacer arrancar su famosa Relectio de Indis prior con un recordatorio de la obligación que tienen príncipes y laicos de seguir el consejo de sus asesores teológicos "in rebus dubiis" 36 .

Aunque la historiografía sobre esta relectio particular y, en general, sobre Vitoria, ha adscrito este imperativo a asuntos bélicos y geopolíticos, se encuentran también algunas menciones a la esfera económica en la Relectio de Indis prior:

Itaque non satis est ad securitatem vitae et conscientiae, ut quis putet se bene agere, sed in rebus dubiiss necesse est, ut aliorum, ad quos expectat, autoritate nitatur. Nec enim negotiatoribus satis est, ut nihil faciant, quod ipsi illicitum putent, si alias sine consilio peritorum illicitus contractus faciant ${ }^{37}$.

Dado que las menciones a la obligación de consulta y la importancia del juicio probable en la esfera económica o sacramental son abundantes -aunque dispersas- en el amplio corpus vitoriano (relecciones y clases comprendidas), nos gustaría regresar a este tema más adelante con un artículo monográfico dedicado al tratamiento de estos temas por Francisco de Vitoria. El contraste entre las posiciones de Vitoria, Mercado y otros maestros, nos parece, de hecho, importantísimo para entender la emergencia y evolución de la filosofía probabilista y los métodos de argumentación de la teología moral en la Primera Modernidad.

36 "In rebus dubiis quilibet tenetur consulere illos, ad quos spectat docere, alias non est tutus in conscientia, sive illa dubia sint de re in se licita sive illicita", Francisco de Vitoria, De Indis et De Iure Belli Relectiones (ed. by Ernest Nys) (Washington: The Carnegie Institution of Washington, 1917), p. 221. "En materia dudosa debe consultarse con aquellos a quienes compete instruir sobre el caso; de otro modo, no está seguro en su conciencia, sea realmente en sí lícita o ilícita aquella materia", Francisco de Vitoria, Relectio De Indis, trad. cast. de Luciano Pereña, Carlos Baciero y Francisco Maseda (Madrid: CSIC, 1989), 60.

37 Francisco de Vitoria, De Indis et De Iure Belli Relectiones, p. 220. "No es, pues, suficiente para la tranquilidad de la vida y de la conciencia que uno piense que obra bien, sino que es preciso en las cosas dudosas apoyarse en la autoridad de aquellos a quienes compete. Pues no basta que los mercaderes se abstengan de lo que ellos mismos creen ilícito, si por otra parte realizan contratos no lícitos, prescindiendo del asesoramiento de juristas", Francisco de Vitoria, Relectio De Indis, 59. 


\section{V. ¿UNA BERUFSETHIK PARA LOS MERCADERES? DIFERENCIACIÓN DE ÉTICAS PROFESIONALES Y SUPERVIVENCIA DE LA NORMATIVIDAD CRISTIANA EN EL MUNDO MODERNO.}

Volviendo a la Suma de Mercado, nos gustaría incidir en la reflexión que hicimos antes al considerarla como una importante contribución intelectual al perfilamiento de una Berufsethik para el gremio de los mercaderes. Tras un largo período en el que tanto los procesos de profesionalización y especialización laboral como sus respectivos marcos normativos se consideraron innovaciones relativamente recientes y exclusivas del mundo contemporáneo, la historiografía comienza a abordar determinadas contribuciones o hitos históricos que reflejan que, más que un resultado de rupturas o innovaciones abruptas, este tipo de procesos tiene que ver con dinámicas de larga duración y aportaciones provenientes, en ocasiones, de esferas insospechadas. En este sentido, determinadas obras adscritas a la teología moral del Tardo-Medievo o la Primera Modernidad, tanto hispano-americanas ${ }^{38}$ como producidas en otras latitudes $^{39}$, dejan de ser prejuzgadas superficialmente como instrumentos de homogeneización moral y religiosa de la sociedad y comienzan a ser apreciadas en ellas aquellos elementos que resultan contribuciones relevantes en un proceso de emergencia de las éticas profesionales que, en realidad, viene perfilándose desde la Antigüedad.

En el caso de Mercado, oponiéndose, como vimos, a los extremos representados por un total rigorismo o laxismo, se realizan transformaciones de gran calado en lo que podríamos considerar como una normatividad cristiana general, con el objeto de adaptarla a los desafíos morales específicos que en su praxis diaria debían afrontar los mercaderes de la época. Este esfuerzo de adaptación no se restringe, por supuesto, ni en la filosofía occidental ni en la

38 La literatura sobre la ética económica de la escolástica española sigue creciendo en cantidad y calidad. Los trabajos pioneros de Majorlie Grice Hutchinson, Early Economic Thought in Spain, 1170-1740 (Londres: Allen and Unwin, 1975) o Alejandro Chafuen -Christians for Freedom: Late Scholastic Economics (San Francisco: St. Ignatius Press, 1986), interesantes aunque cargados de anacronismos y pasajes hagiográficos, han dado paso a obras más equilibradas y 'académicas', sobre todo desde la publicación del influyente libro de Oreste Popescu, Estudios en la Historia del Pensamiento Económico Latinoamericano (Bogotá: Plaza \& Janés, 1986).

39 El aporte más sistemático y reciente es el de Roberto Lambertini, "Economic Ethics", en: The Cambridge Companion to Medieval Ethics, ed. por Thomas Williams (Cambridge: Cambridge University Press, 2019), 306-324. Otros textos en los que prima una reflexión metodológica y conceptual sobre el tema que nos ocupa, Daniel Wren, "Medieval or Modern? A Scholastic's View of Business Ethics, circa 1430", Journal of Business Ethics, 28, $\mathrm{n}^{\circ} 2$ (2000): 109-119; Jennifer Hole, Economic Ethics in Late Medieval England, 1300-1500 (Londres: Palgrave Macmillan, 2016). 
teología cristiana a la profesión del mercader. Desde la Antigüedad, la historia de ambas disciplinas nos ofrece interesantes reflexiones sobre los cometidos propios a los oficios de gobernantes, embajadores, legisladores, jueces, soldados, profesores, etc. Estas dinámicas de diferenciación normativa se incrementan, en todo caso, en la Modernidad Temprana, donde las transformaciones económicas, la escisión de la Cristiandad o el refuerzo de la autoridad de las príncipes hacen que las pautas singulares de acción propias de cada oficio y las situaciones excepcionales en las que un cierto profesional puede considerarse dispensado del seguimiento de una norma general, se conviertan en el foco principal de la reflexión ética, jurídica y política. La vasta literatura producida en la época sobre el omnipresente tema de la razón de estado y el derecho de los príncipes a actuar - caso de resultar necesario- contra las leyes naturales, divinas y positivas es, seguramente, el ejemplo más estudiado de estas dinámicas de diferenciación normativa.

También la perspectiva teológico-moral relativamente laxa expuesta en la Suma de Mercado, de acuerdo a la cual el teólogo experimentado debía incluso dar "muchas vezes gran libertad y aun autoridad" 40 a su pupilo, asesorado o penitente, no se concibe como una recomendación general y aplicable a cada laico, sino como una concesión específica a las necesidades y condicionantes propios de oficios como el de mercader o cambista, que, aunque útiles para la República, no podrían existir si se obligara a los miembros de estos gremios a seguir un marco normativo rigorista y sin capacidad para distinguir entre prácticas necesarias, buenas y óptimas.

Considerando en clave realista que el afán de lucro y el interés son la esencia de la actividad comercial y que condenarlos equivaldría a obligar al mercader a dejar su oficio, privando al mismo tiempo a la República de medios indispensables para su supervivencia y prosperidad, Mercado lanza una clara advertencia frente a todo intento de regulación de las prácticas mercantiles mediante un marco normativo cargado de rigor y escrúpulos:

[...] que cierto el letrado, corto, falto de experiencia y cargado de escrupulos, no es convenible para el mercader [...]. Y no se yo porque, preguntandome uno si podra ganar en esto: concediendole muchos authores graues y doctos la ganancia, se la e de quitar yo, o vedar por solo que soy de contrario parecer, destos casos ay cien mil en theologia moral [...]. Por lo qual deue el confessor, y theologo no ser tan amigo de sus conceptos: que tenga todos los 
otros por borrados sino ser discreto, discernir entre lo que ay euidencia, o sola opinión y probabilidad, y no tener cada cosa en mas de lo que es ${ }^{41}$.

En la perspectiva de Mercado, la intervención del confesor para prohibir un cierto trato o negocio sin dejar margen de acción alguno para su asesorado o penitente, sólo se justifica cuando el teólogo está absolutamente seguro de que no está defendiendo una "sola opinion y probabilidad", sino una "evidencia"42. En ausencia de esta certeza, tan difícil de encontrar en una teología moral en la que, como el mismo Mercado indica, hay "cien mil" casos dudosos y regulables tan sólo mediante alternativas probables, el confesor o consejero religioso debe dejar claro al mercader que sólo le está proponiendo la opción de actuación que él considera más segura para la conciencia, abriéndole la puerta, por lo demás, a que el aconsejado actúe de acuerdo a su propia inclinación o criterio, si éste resulta bien fundado.

In dubio melior est opinio mercatoris [ante la duda, mejor seguir la opinión del mercader]. Aunque Mercado no reescribió en su obra en castellano el famoso adagio Latino (In dubio melior est conditio possidentis [ante la duda, es mejor la condición del poseedor]), ni se trata de palabras que el sevillano llegara seguramente a pronunciar, podrían considerarse una buena síntesis de sus posiciones y del contraste que marcan con la literatura de confesores precedente. Nos parece que cuando Mercado exhorta a sus colegas a "no ser tan amigo[s] de sus conceptos" y a los mercaderes penitentes a evitar al confesor "cargado de escrupulos", está realizando una contribución de primer orden a la redefinición del marco normativo bajo el cual la teología moral podía tener aún una cierta relevancia y eficacia reguladora en un mundo moderno en el que el comercio y la banca emergían como principales actividades económicas y lideraban un ciclo de transformación que, por primera vez en la historia, se extendía a la totalidad del planeta.

Haciendo un análisis detallado de los riesgos crecientes entrañados específicamente por el gremio de los mercaderes, Mercado es consciente de que un enfoque rigorista no serviría más que para apartar totalmente a amplios sectores de la población de los clérigos y de su asesoramiento normativo, convirtiendo además a la teología moral una jerga estéril y desvinculada totalmente de la praxis y vida real. Para evitar o tratar de minimizar, al menos, esta desconexión creciente entre el mundo de los hechos y el de los valores y preceptos morales y religiosos, Mercado manifiesta explícitamente su intención

41 Ibid., f. $14 \mathrm{v}-15 \mathrm{v}$.

42 Ibid., f. $15 \mathrm{v}$. 
de abstenerse de recomendar "lo mejor y mas seguro"43 y limitarse a enseñar "lo que es licito o ilícito". Observamos un salto sustancial de lo que podríamos considerar una ética de máximos a una ética de mínimos redactada a la manera de un breve compendio de prohibiciones absolutas. Tras identificar estas pocas líneas rojas, Mercado perfila un amplio campo de zonas grises en las que diferentes alternativas de acción son probables, invitando a confesores y penitentes a la evaluación prudencial de los factores y condicionantes que subyacen a cada uno de los casos que corresponden a esta tipología. Resulta importante sopesar al detalle las pocas palabras en las que Mercado condensa los principios que le han orientado en el proceso de escritura de su obra:

Algunos varones religiosos y doctos he visto, que tratando esta materia tan llena de ñudos ciegos, despues que an hablado harto se resuelven que lo mejor de los dados. \& c. y dan en persuadir a sus amigos, busquen otro modo de bivir y dexen este, yo no quise en este opúsculo ser predicador, sino doctor, no rethorico facundo y elegante, sino theologo moral, claro y breve, asi no escrivo persuadiendo y exhortando lo mejor y mas seguro, sino enseñando lo que es licito e ilícito: en lo demas, cada uno se aconseje con su confessor: y pues el trato (dado que es ocasionado para mal) se puede (aunque con dificultad) exercitar bien: mi fin será mostrar que intento deve tener el mercader en sus negocios, que medios a de escoger, para que pueda ganar de tal modo su vida, que no pierda la futura: lo demas que es persuadirles se aparten totalmente del trato, no me quise agora detener en hazerlo, lo vno viendo que no an acabado cosa los que en ello se han detenido, lo otro y principal considerando la suspensión en que quedo el glorioso S. Augustin, començando vna vez a persuadir esto en el psal. $70 .^{44}$.

Al distanciarse del enfoque tutiorista, Mercado está, en realidad, perfilando el tipo de análisis pragmático que debe caracterizar el trabajo del confesor y consejero religioso en el futuro -al menos en la esfera de los tratos y contratosy redefiniendo, por ende, la misma disciplina de la teología moral para que pudiera tener aún alguna funcionalidad y aplicabilidad en un contexto de prácticas y dinámicas mercantiles que, de creación reciente, estaban llamadas a durar "algunos siglos" ${ }^{45}$, como el mismo Tomás de Mercado entrevé en su

43 Distanciándose, por tanto, sin ningún tipo de ambages, del tutiorismo, "which obliged the agent to follow the course of action that best ensures that the agent would avoid sin", Tutino, Uncertainty in post-Reformation Catholicism: a History of Probabilism, 1.

44 Mercado, Tratos y contratos de mercaderes, ff. 9r-9v.

45 "Queriendo pues imitar a estos que en affecto, y obras, fueron verdaderos padres, y mirando el estado presente destos reynos, y de todas las Indias, y que creo durara algunos siglos, me parescio que de muchas cosas, que provechosamente se pueden tratar, y es necessario se traten, seria ocupacion 
compendio. El enfoque tutiorista que, antaño había monopolizado prácticamente la literatura de confesores, sale en cambio de la lista de cometidos del teólogo moral, para considerarse como propio o requerible del pastor y predicador, responsable de educar al conjunto del rebaño cristiano en unos estándares morales de mayor rigor y tendentes a incentivar en la masa indiferenciada una conducta óptima.

\section{LA SUMA DE TRATOS Y CONTRATOS, INICIATIVA COMÚN DE LA FACULTAD DE TEOLOGÍA DE SALAMANCA.}

Aunque, seguramente, este juicio resulte un tanto anacrónico para definir el pensamiento de Tomás de Mercado, nos parece que su Suma de tratos y contratos refleja una incipiente emergencia de éticas profesionales diferenciadas en la teología moral de la época, proceso que vendría a sumarse y radicalizar la ya anteriormente marcada multinormatividad que distinguía el tipo de análisis de casos problemáticos que encontramos en la literatura de confesores y otros géneros propios de esta disciplina del saber. En el tipo de enfoque casuista por el que parece apostar Mercado -en el que el recurso a opiniones probables y el análisis multinormativo resultan esenciales- resulta esencial la armonización de la interacción entre diferentes criterios morales personales y corporativos o gremiales. Todos estos elementos son identificados por Mercado no sólo como los retos a abordar por la moral cristiana de la época, sino como auténticos dilemas de cuya respuesta dependía la misma supervivencia del rico patrimonio de normatividad cristiana en un mundo en transformación y sacudido hasta los cimientos por un inédito -e inesperadoproceso de expansión global de las redes mercantiles.

En otras palabras, creo que Mercado -y junto a él, otros clarividentes teólogos escolásticos de su tiempo-, es consciente del hecho de que o se admitían y definían estándares morales particulares de validez probable y que guardaran correspondencia con los fines, necesidades y prácticas específicas de las distintas corporaciones que integraban una sociedad cada vez más compleja o la moral cristiana estaba condenada a convertirse en una jerga muerta sin efecto práctico alguno. Nos parece que este objetivo pragmático constituye un factor esencial del proceso de emergencia de la filosofía probabilista y que no es, por tanto, casual, que sea una suma sobre tratos y contratos de mercaderes la que contenga una de las primeras exposiciones metodológicas de cierta extensión -

util mostrar con claridad, como exercitarian los mercaderes licitamente su arte con los demas negocios annexos, y consequentes de cambios y vsuras", Ibid., "Prologo", [s.p.]. 
aunque no completamente sistemática- sobre la forma de conciliar diversas opiniones probables.

La Suma de Mercado fue, además, aprobada, elogiada y recomendada como lectura indispensable para los profesionales de la confesión por algunos de los más importantes teólogos dominicos, agustinos y benedictinos de la época. Encontramos este apoyo masivo a la obra en las ocho censuras y decretos que, junto a la licencia y el parecer prescriptivos y la "Epístola nuncupatoria al insigne y celebre Consulado de Mercaderes de Sevilla" y el "Prólogo" escritos por el propio Mercado, sirven de introducción a los Tratos y contratos. Aunque la licencia del Consejo Real, encargado de designar a los expertos que examinarían un cierto libro - fray Bernardino de Alvarado, prior del convento de San Agustín de Toledo, en este caso- y de los superiores de la orden a la que estuviera adscrito su autor, si éste era un fraile-fungiendo Alonso de Hontiveros, Vicario general de la Provincia Dominica de España, como autoridad que proporcionó la respectiva licencia de impresión- eran imprescindibles en la época para que cualquier libro pudiera ver la luz ${ }^{46}$, Mercado se esforzó por obtener un apoyo suplementario excepcional para su obra. Con este fin, 'cortejó' a los principales catedráticos de teología de la Universidad de Salamanca y obtuvo de ellos y otros autores de referencia ocho censuras que elogiaban su obra y la recomendaban en tanto que "util y provechosa para todos los tratantes, y para los confessores, y predicadores, y aun para los que ensenan, y leen aunque sean cathedraticos" ${ }^{\$ 7}$. Los titulares de las cátedras Prima de Teología -en este período, el dominico Mancio de Corpus Christi ${ }^{48}$ - y Vísperas de Teología -el agustino Juan de Guevara ${ }^{49}$-, aprobaron la obra con grandes loas. También Francisco Sancho ${ }^{50}$ y Diego Rogríguez ${ }^{51}$, miembros del clero secular y titulares respectivos de las cátedras de Filosofía Moral y Santo Tomás, se deshicieron en

46 Un acercamiento general a la legislación relativa a la impresión y venta de libros tras la publicación de la transcendental pragmática dictada por Felipe II en 1558 en Juan Friede, "La censura española del siglo XVI y los libros de historia de América", Revista de Historia de América 47 (1959): 45-94, espec. 49-50.

47 De acuerdo a la censura escrita por el destacado teólogo Mancio de Corpus Christi, "Censura del sapientißimo maestro el padre fray Mantio de la Orden de los Predicadores cathedratico de prima, en Theologia en Salamanca”, en: Mercado, Tratos y contratos de mercaderes, [s.p.].

48 Ocupó la cátedra entre noviembre de 1564 y julio de 1576, Barrientos García, La Facultad de Teología de la Universidad de Salamanca a través de los libros de visitas a cátedras (1560-1641), 174-201.

49 De marzo de 1565 a agosto de 1600, Ibid., 329-364

50 A partir de 1549 y hasta su muerte, acaecida en julio de 1578. Ver Ana María Carabías Torres, Salamanca y la medida del tiempo (Salamanca: Universidad de Salamanca, 2012), 197-198 y José Barrientos García, "Fray Luis de León, profesor de la Universidad de Salamanca", en, Fray Luis de León. Historia, Humanismo y Letras, ed. por Víctor García De la Concha y Javier San José Lera (Salamanca: Universidad de Salamanca, 1996), 93.

$51 \mathrm{Al}$ frente de la cátedra de Santo Tomás entre enero de 1567 y julio de 1594. 
cumplidos con Mercado y su Suma. Incluso los teólogos agustinos con mayor fama en la época, fray Luis de León -quien, en ese momento, ocupaba la Cátedra de Nominales ${ }^{52}$ - y Alonso de la Vera Cruz, se sumaron al coro laudatorio de un "libro muy acertado, y provechoso", escrito por un autor "de mucho ingenio" 53 .

En el caso de Vera Cruz, que no pertenecía al cuerpo de catedráticos salmantinos, creemos que Tomás de Mercado pudo solicitar su apoyo como aval del amplio contenido experiencial relacionado con asuntos de Indias incluido en la obra. A pesar de que desde finales de la década de $1550^{54}$ Vera Cruz ya no había podido ejercer la docencia universitaria, el título del "decreto" aprobatorio firmado con su nombre lo presenta como "sapientißimo maestro" -al igual que el de Mancio- y como "cathedratico de prima en la universidad de Mexico".

Al respaldo obtenido por parte de todos estos catedráticos de universidad, se sumaron también los de otros teólogos importantes que residían por aquel entonces en Salamanca, el del abad general de los benedictinos, Alonso Zorrilla y el del canónigo penitencial de la Iglesia de Salamanca y doctor en teología, Pedro de Fuentidueña.

Es importante tener en cuenta que la mayoría de los teólogos que otorgaron su aval a la Suma de tratos y contratos habían sido discípulos de Vitoria dos o tres décadas antes. Se trata por tanto de miembros de la que podríamos considerar como segunda generación de la Escuela de Salamanca, es decir, la generación inmediatamente precedente al que la historiografía ha considerado como padre del probabilismo, el dominico Bartolomé de Medina, que ocupó la cátedra Prima de Teología desde la muerte de Mancio de Corpus Christi, acaecida en julio de $1576^{55}$.

Como José Barrientos -seguramente el mejor conocedor vivo de los intríngulis de la vida académica en Salamanca- subrayó hace algunos años,

52 La ocupó entre marzo de 1565 y marzo de 1573 , momento en el que se vio obligado a renunciar a la misma tras ser encarcelado por la Inquisición, Barrientos García, La Facultad de Teología de la Universidad de Salamanca a través de los libros de visitas a cátedras (1560-1641), 695-715.

53 Ibid., "Censura del muy reverendo padre, el maestre fray Luis de Leon, cathedratico en Theologia en la universidad de Salamanca", [s.p.].

$54 \mathrm{Y}$ debido, primero, a sus cometidos como misionero y, después, a su marcha forzosa a España, que se produjo en mayo de 1562. Vera Cruz tuvo que abandonar de mala gana la región de Michoacán, donde ejercía una importante función como evangelizador de los naturales. Su desplazamiento a España fue obligado tras haber sido denunciado ante la Inquisición por el arzobispo de México, Alonso de Montúfar, quien le reprochaba especialmente el oponerse a que la Iglesia secular exigiera el pago de diezmos a los indígenas en proceso de indoctrinación. Rafael Lazcano, Fray Alonso de Veracruz (1507-1584). Misionero del saber y protector de indios (Guadarrama: Revista Agustiniana, 2007), 68-73.

55 Medina fue catedrático de Prima de Teología entre julio de 1576 y finales de 1580. 
teniendo en cuenta la cantidad y calidad de las censuras aprobatorias incorporadas a la Suma de Mercado, podríamos hablar de un apoyo excepcional concedido por la Facultad de Teología de Salamanca a una obra impresa, elemento que, en realidad, nos permite ir más allá y considerar este tratado de moral mercantil como una iniciativa común de la Facultad ${ }^{56}$, algo que el mismo Mercado insiste en subrayar en la "Epistola nuncupatoria" que abre su escrito:

Por lo qual desseando la utilidad y honrra verdadera de essas gradas procure, que dado yo solo compusiesse la obra, muchos varones mas antiguos en dias, y letras, que yo casi fuessen autores della (conuiene a saber) todos los cathedraticos en Theologia desta universidad de Salamanca, y otros muchos maestros, de gran erudición, como abaxo van nombrados, examinándola ya compuesta, y aprobando su doctrina, cada uno de los quales la passo por si, y la censuro, de manera que se pueden asegurar con ella, y holgarse de tener resueltos y determinados sus contratos, por toda esta famosa universidad do al presente, y siempre se conservo, y florescio toda doctrina verdadera, ansi natural y moral, como divina ${ }^{57}$.

\section{CONCLUSIONES. UN PROGRAMA DE INVESTIGACIÓN POR REALIZAR. HACIA UNA PRE-HISTORIA DEL PROBABILISMO Y DE LA EMERGENCIA DE UNA TEOLOGÍA MORAL MERCANTIL EN LA ESCUELA DE SALAMANCA.}

En nuestra opinión, el respaldo que ofrecen los teólogos de Salamanca a la obra debe entenderse tanto como una muestra de adhesión a sus contenidos, "doctrina muy provechosa", como -y especialmente-, un claro aval al enfoque o metodología recomendada por Mercado para resolver muchos de los casos y dudas que analiza en su Suma. Resulta, de hecho, totalmente implausible que las innovaciones metodológicas que Mercado puso en práctica en su obra acercándose muchísimo a un modo de proceder propiamente probabilista-

56 Barrientos ha sostenido también una opinión semejante en otra de sus obras recientes. "De la Escuela de Salamanca solamente aparece citado Domingo de Soto, exactamente en 48 ocasiones, pero Mercado depende de la Escuela mucho más de lo que el número de citas puede dar a entender, pues se formó en su espíritu que supo transmitir con gran fidelidad. No en vano la propia Escuela avaló la publicación de la Suma, pues cuenta con las censuras favorables de los profesores de Teología siguientes: Mancio de Corpus Christi, Juan de Guevara, fray Luis de León, Diego Rodríguez y Francisco Sancho, lo que quiere decir que, de las cinco cátedras de Teología escolástica que tenía la Universidad de Salamanca, cuenta con el apoyo de cuatro de sus catedráticos, más el del decano del colegio de teólogos, el maestro Francisco Sancho", José Barrientos García, Repertorio de moral económica (15361670) (Pamplona: EUNSA, 2011), 21-22.

57 Mercado, Tratos y contratos de mercaderes, "Epistola nuncupatoria", [s.p.]. 
llegaran a pasar desapercibidas para teólogos agudos y meticulosos como Luis de León, Alonso de la Vera Cruz o Mancio de Corpus Christi. Si consideramos además que la mayoría de los teólogos que aprobaron la obra habían sido, a su vez, maestros de Mercado en Salamanca ${ }^{58}$ o en México -caso de Vera Cruz- no es descabellado suponer que el método casuístico empleado por Mercado estuviera, a su vez, influenciado por doctrinas aprendidas de estos maestros.

De hecho, una investigación exhaustiva en la pre-historia del probabilismo más inmediata debería examinar el papel que la opinión probable juega en los teólogos de la Escuela entre la década de los treinta -analizando desde esta óptica las Relecciones y cursos de Vitoria ${ }^{59}$ - y la década de los sesenta, período en el que figuras como Mancio de Corpus Christi, Luis de Léon o Juan de Guevara son los que llevan la batuta en la Facultad de Teología de la Universidad de Salamanca. Tampoco habría que olvidar a una figura central en este asunto como es Domingo de Soto, quien en su manuscrito De dubio et opinione $^{60}$-reflejo de las clases que dedicó en Salamanca a los artículos 5 y 6 de la quaestio 19 de la Ia-IIae, los mismos sobre los que Bartolomé de Medina cimentará más tarde su doctrina plenamente probabilista- ya había debatido por extenso acerca de la duda y la probabilidad y la actitud que debía adoptar el confesor al encontrarse con un penitente renuente a abandonar su propia opinión probable $^{61}$.

El apoyo dado por la Facultad de Teología de Salamanca a la obra de Mercado resulta crucial para la historia de la filosofía y del derecho por varios

58 Barrientos García, Repertorio de moral económica (1536-1670), 218.

59 Aunque de forma muy esquemática y sucinta, Bonifacio Palacios se refirió ya al uso de la opinión probable en Vitoria, Cano y Soto en su contribución a la Historia de la teología española coordinada por Melquiades Andrés. Bonifacio Palacios, "Teología Moral y sus aplicaciones, 15801700", en Historia de la Teología Española, ed. por Melquiades Andrés (Madrid, Fundación Universitaria Española, 1987), 161-179. Siguiendo a Palacios, González Polvillo insistió también en fechas más recientes en subrayar que en sus comentarios a la Ia-IIae y en la Breve Instruction de cómo se ha de administrar el Sacramento de la Penitencia (Salamanca: Herederos de Mathias Gast, 1579), Medina no hizo "más que seguir, culminar en realidad, algo que ya habían tocado sus antecesores en la cátedra salmantina como Francisco de Vitoria, Melchor Cano y Domingo de Soto, en torno a la opinión probable en relación con la conciencia". Lamentablemente y, como en el caso de Palacios, se da por hecho esta conexión, pero no se estudia al detalle ni se prueba con una sólida base textual. Antonio González Polvillo, Análisis y repertorio de los tratados y manuales para la confesión en el mundo hispánico (ss. XV-XVIII) (Huelva: Universidad de Huelva, 2009), 99.

60 Domingo de Soto, De dubio et opinione, en: Joseph Ternus, Zur Vorgeschichte der Moralsysteme von Vitoria bis Medina. Neue Beiträge aus gedruckten und ungedruckten Quellen (Padeborn: Schöningh, 1930), 54-61. Editado en traducción castellana en Francisco O’Reilly, Duda y opinión. La conciencia moral en Soto y Medina (Pamplona: EUNSA, 2006), 51-63.

61 Las afinidades y diferencias entre Soto y Medina son las que mejor han sido estudiadas hasta la fecha en la obra de Francisco O'Reilly arriba citada. Duda y opinión. La conciencia moral en Soto y Medina. 
motivos. Por un lado, ilustra con una claridad meridiana el gran interés y compromiso que existía en el seno de la Facultad por favorecer la renovación y adaptación de los métodos teológico-morales a los nuevos tiempos, así como el tremendo arraigo de las doctrinas proto-probabilistas en el seno de la Facultad. Ello nos permite ver las posiciones de Bartolomé de Medina en clave de continuidad y entender el origen del probabilismo más como un proceso de emergencia progresivo, que como una ruptura revolucionaria llevada a cabo por el genio Medina. El propio Medina subraya, de hecho, esta continuidad con una humildad casi excesiva en su Expositio in Primam Secundae, sugiriendo que su labor ha sido, ante todo, la de compilar, sintetizar y actualizar los comentarios manuscritos a la Summa tomista que habían escrito los grandes maestros que le habían precedido en Salamanca. Menciona, en este sentido, a Vitoria, Soto, Cano, Sotomayor, Pena y Mancio, dedicándoles grandes cumplidos ${ }^{62}$.

Por otro lado, dada además la importancia que el Estudio salmantino tenía en tanto que uno de los principales centros intelectuales del mundo católico en la época, tanto la obra de Mercado como el hecho de que sea una iniciativa común de la Facultad de Teología, deberían considerarse como elementos de juicio esenciales para que, de una vez por todas ${ }^{63}$, se destierren las famosas especulaciones metahistóricas de Weber sobre la incapacidad de los intelectuales católicos de la Primera Modernidad para construir sistemas teológico-morales que, en su intento por regular el afán de lucro característico de la ética profesional de mercaderes y banqueros, no acabaran criminalizándolo o estigmatizándolo $^{64}$.

62 Ver la epístola dedicatoria dirigida al que por entonces era Maestro general de la Orden dominica, Serafín Cavalli. Bartolomé de Medina, "Reverendissimo, ac dignissimo Patri nostro Seraphino Cavalli Brixiensi, totius Ordinis Praedicatorum Magistro Generali”, en Expositio in Primam Secundae, [s.p.].

63 Una reseña sobre las críticas que desde la recepción pionera de Felix Rachfahl recibió $L a$ ética protestante y el espíritu del capitalismo por la incapacidad de Weber para ofrecer "sufficient evidence to substantiate his own thesis" y la superficialidad que denota "his use of sources", en Alastair Hamilton, "Max Weber's Protestant Ethic", en, The Cambridge Companion to Weber, ed. por Stephen Turner (Cambridge: Cambridge University Press, 2000), 151-171, espec. 161-171.

64 Esta parte del ideario weberiano adolecería no sólo de graves fallos en tanto que reconstrucción poco fidedigna de la historia de las ideas políticas y económicas en la Modernidad Temprana, sino también en el plano epistemológico. "Weber does have an implicit sense of the importance of a cultural apparatus that facilitates market activity. But he fails to separate it from the question of motivation and seems to hold that the relevant directing and facilitating forces for capitalist action derive from Protestant or are inhibited by Catholic religious values [...]. A major difficulty with Weber's approach [...] is the impossibility of demonstrating such a motivational connection. It is possible to go no further than hypothesize that such a connection exists", Jack Barbalet, Weber, Passion and Profits (Cambridge: Cambridge University Press, 2008), 105-106. 
Cuando Weber afirmó en La ética protestante y el espiritu del capitalismo que, desde Tomás de Aquino, el pensamiento ético católico se había estancado en una "doctrina dominante [que] rechazó como turpitudo el "espíritu" del lucro capitalista o al menos no pudo valorarlo éticamente de una manera positiva" ${ }^{65}$, sólo demostró, en realidad, su tremenda ignorancia acerca de la rica literatura y grandes innovaciones metodológicas y conceptuales que teólogos-morales como Mercado - un intelectual que, ya en el siglo XVI, es global en su formación, trayectoria de vida y pensamiento- comienzan a desarrollar pocas décadas después del descubrimiento de las Indias. En obras como la Suma de tratos y contratos se estudian desde perspectivas diferenciales los "cien mil casos" que les planteaban "los negocios de mercaderes que comunmente son de interes" 66 en ciudades hispánicas y católicas como Sevilla, centro desde el que en la época se transfretan no sólo bienes a los cuatro continentes conocidos, sino también, y como hemos visto, tanto una amplia serie de prácticas comerciales como las normatividades que aspiran a regularlas éticamente.

La lectura de los escritos dedicados por Mercado a los fenómenos económicos propios de su tiempo revela en su carácter de simplificación grosera y prejuicio cultural la perspectiva weberiana-sorprendemente longeva- de que para los pensadores católicos del Antiguo Régimen "an ethical businees is an oximoron" ${ }^{67}$. No hay nada de ignominioso y turpis en la perspectiva con la que Mercado describe y después, intenta regular, en una obra dedicada justamente

65 Max Weber, La ética protestante y el espíritu del capitalismo (Madrid: Akal, Istmo, 2013), p. 130. Dado su interés, citamos con más amplitud el párrafo que condensa las ideas de Weber sobre el estancamiento de la teología-moral católica y su incapacidad para adaptarse a la economía mercantil moderna en su versión original: "In dem in das kanonische Recht übergangenen, damals (ebenso wie die Stelle des Evangeliums von Zins) für echt gehaltenen Satz "Deo placere vix potest", der von der Tätigkeit des Kaufmanns wurde, in der Bezeichnung des Gewinnstrebens durch Thomas als turpitudo (mit der selbst das unvermeidliche und daher ethisch erlaubte Gewinnmachen belegt wurde), lag, gegenüber den radikal antichrematistichen Ansichten ziemlich breiter Kreise, schon ein hoher Grad von Entgegenkommen der katholischen Doktrin gegenüber den Interessen der mit der Kirche politisch so eng liierten Geldmächte der italienischen Städte. Und auch wo die Doktrin noch mehr sich akkommodierte, wie namentlich etwa bei Antonin von Florenz, schwand noch die Empfindung niemals ganz, daß es sich bei der auf Erwerb als Selbstzweck gerichteten Tätigkeit im Grunde um ein pudendum handle, welches nur die einmal vorhandenen Ordnungen des Lebens zu tolerieren nötigten. Einzelne damalige Ethiker vor allem der nominalistichen Schule nahmen die entwickelten Ansätze kapitalistischer Geschäftsformen als gegeben hin, und suchten sie als statthaft, vor allem den Handel als nötig, die darin entwickelte ,industria“ als legitime Gewinnquelle und ethisch unanstößig zu erweisen: -nicht ohne Widerspruch,- aber den „Geist“ des kapitalistischen Erwerbes lehnte die herrschende Lehre als turpitudo ab oder konnte ihn mindestens nicht positiv ethisch werten", Max Weber, Die protestantische Ethik und der Geist des Kapitalismus / Die protestantischen Sekten und der Geist des Kapitalismus. Schriften 1904-1920 (Tübingen: Mohr Siebeck, 2016), 195-203.

66 Mercado, Tratos y contratos de mercaderes y tratantes, f. $15 \mathrm{r}$.

67 David Vogel, "Business Ethics' Ethical Roots”, Business Ethics Quarterly, 1, n 1 (1991): 107. 
"Al insigne y celebre, consulado de Mercaderes de Sevilla" ${ }^{68}$, las complejas prácticas mercantiles y ocupaciones diarias en las que vivían enfrascados sus conciudadanos de Sevilla ${ }^{69}$. Al contrario, su actitud es la de un sevillano más, confesor y teólogo y al mismo tiempo nacido y educado en una familia de mercaderes. Se trata de un mix o combinación que hubiera desconcertado un tanto a Weber, pero es casi regla general en los teólogos de la Escuela de Salamanca desde su mismo fundador, Vitoria, criado en una familia de comerciantes burgalenses. Más que avergonzado o lleno de escrúpulos ante los riesgos de corrupción moral que el desarrollo comercial y la prosperidad creciente de su ciudad entrañaban, Mercado se muestra lleno de orgullo por el hecho de que su patria se hubiera convertido en la Tiro o la Alejandría de la Modernidad y viviera las páginas más brillantes de su historia:

Ansi la casa de la contratación de Seuilla y el trato della es uno de los mas celebres y ricos que ay el dia de oy, o se sabe en todo el orbe universal, es como centro de todos los mercaderes del mundo, porque a la verdad soliendo antes el Andaluzia y Lusitania ser el extremo y fin de toda la tierra, descubiertas las Indias es ya como medio, por lo qual todo lo mejor y mas estimado que ay en las otras partes antiguas, aun de Turquia viene a ella: para que por aqui se lleve a las nuevas, donde todo tiene tan excessivo precio. De aqui es que arde la ciudad en todo genero de negocios: ay grandes y reales cambios para todas ferias, asi dentro del reyno, como fuera: ventas y compras fiado y de contado de gran summa: muy grandes cargazones: baratas de muchos milliares y cuentos: que ni Tyro, ni Alexandria en sus tiempos se le igualaron ${ }^{70}$.

\title{
REFERENCIAS BIBLIOGRÁFICAS
}

\author{
FUENTES PRIMARIAS
}

68 Ibid., "Epistola nuncupatoria, $\mathrm{Al}$ insigne y celebre, consulado de Mercaderes de Sevilla, el Padre Presentado Fray Thomas de Mercado, gracia, salud, y prosperidad desea", en Mercado, Tratos y contratos de mercaderes y tratantes, [s.p.].

69 Un breve pero agudo análisis del carácter general de los escritos dedicados por los moralistas escolásticos españoles a las profesiones de mercader y banquero en la ya mencionada obra de Melquiades Andrés, La teología española en el siglo XVI. Refiriéndose a autores como Mercado, Soto, Juan de Medina, Azpilcueta o Laínez, Andrés deja claro que en contraste con enfoques rigoristas precedentes: "Nuestros autores rehabilitan y dignifican los oficios de comerciante, tratante y banquero, oficios antiguos y necesarios en la sociedad [...]. La profesión de mercader es indiferente, y, por lo tanto, buena si la intención es recta y lícita", 490.

70 Ibid., f. $2 \mathrm{v}$. 
Azpilcueta, Martín de. Manual de confessores y penitentes. Salamanca: Andrea de Portonaris, 1556.

Cano, Melchor. De locis theologicis. Salamanca: Matthias Gast, 1563.

Cano, Melchor. Los lugares teológicos. Traducción castellana de Juan Belda Plans. Madrid: Biblioteca de Autores Cristianos, 2006.

Chaves, Tomás de, Francisco de Vitoria. Summa Sacramentorum. Valladolid: Sebastián Martínez, 1561.

Chaves, Tomás de Francisco de Vitoria. Confessionario. Santiago: [s.n.], 1562. Concina, Daniele. Della Storia del Probabilismo, e del Rigorismo, Tomo Primo. Venecia: Simone Occhi, 1743.

Medina, Bartolomé de. Expositio in primam secundae Angelici Doctoris D. Thomae Aquinatis. Salamanca: Matthias Gast, 1578.

Medina, Bartolomé de. Breve Instruction de cómo se ha de administrar el Sacramento de la Penitencia. Salamanca: Herederos de Mathias Gast, 1579. Mercado, Tomás de. Tratos y contratos de mercaderes y tratantes discididos y determinados, por el Padre Presentado Fray Thomas de Mercado, de la orden de los Predicadores. Salamanca: Matthias Gast, 1569.

Mercado, Tomás de. Summa de tratos, y contratos. Compuesta por el muy Reverendo Padre Fray Thomas de Mercado de la Orden de los Predicadores, Maestro en sancta Theologia. Dividida en seis libros. Sevilla: Hernando Díaz, 1571.

Soto, Domingo de. De iustitia et iure. Salamanca: Andrea de Portonaris, 1553.

Soto, Domingo de. De dubio et opinione. En Francisco O'Reilly, Duda y opinión. La conciencia moral en Soto y Medina. Pamplona: EUNSA, 2006, pp. 5163.

Vitoria, Francisco de. De Indis et De Iure Belli Relectiones. Editado por Ernest Nys. Washington: The Carnegie Institution of Washington, 1917.

Vitoria, Francisco de. Relectio De Indis. Traducción castellaca de Luciano Pereña, Carlos Baciero y Francisco Maseda. Madrid: CSIC, 1989.

Weber, Max. La ética protestante y el espíritu del capitalismo. Madrid: Akal, Istmo, 2013.

Weber, Max. Die protestantische Ethik und der Geist des Kapitalismus / Die protestantischen Sekten und der Geist des Kapitalismus. Schriften 19041920. Tübingen: Mohr Siebeck, 2016.

\section{BIBLIOGRAFÍA SECUNDARIA}

Andrés, Melquiades. La teología española en el siglo XVI. Madrid: Biblioteca de Autores Cristianos, 1977.

Barbalet, Jack. Weber, Passion and Profits. Cambridge: Cambridge University Press, 2008. 
Barrientos García, José. "Fray Luis de León, profesor de la Universidad de Salamanca". En Fray Luis de León. Historia, Humanismo y Letras. Editado por Víctor García De la Concha y Javier San José Lera, 81-118, Salamanca: Universidad de Salamanca, 1996.

Barrientos García, José. Repertorio de moral económica (1536-1670). Pamplona: EUNSA, 2011.

Barrientos García, José. La Facultad de Teología de la Universidad de Salamanca a través de los libros de visitas a cátedras (1560-1641). Madrid, Porto: Sindéresis, 2018.

Bernal, Antonio-Miguel. "Tomás de Mercado y las 'negociaciones' con las Indias", en: Tomás de Mercado, Tratos y contratos de mercaderes y tratantes. Edición facsimilar, 43-69. Salamanca: Universidad de Salamanca, 2015.

Burke, Peter. "Cultures of Translation in Early Modern Europe". En Cultural translation in Early Modern Europe. Editado por Peter Burke, Ronnie PoChia Hsia (eds.), 7-38. Cambridge: Cambridge University Press, 2007.

Carabías Torres, Ana María. Salamanca y la medida del tiempo. Salamanca: Universidad de Salamanca, 2012.

Carrillo Cazares, Alberto. "Un tratado perdido de fray Pedro de Pravia", Anuario de Historia de la Iglesia 16 (2007): 355-360.

Chafuen, Alejandro. Christians for Freedom: Late Scholastic Economics. San Francisco: St. Ignatius Press, 1986.

Delumeau, Jean. L'Aveu et le Pardon. Les difficultés de la confession. XIIIeXVIIIe siècle. Paris: Fayard, 1992.

Duve, Thomas. "Katholisches Kirchenrecht und Moraltheologie im 16. Jahrhundert: Eine globale normative Ordnung im Schatten schwacher Staatlichkeit". En Recht ohne Staat? Zur Normativität nichtstaatlicher Rechtsetzung. Editado por Stefan Kadelbach, Klaus Günther, 147-174. Frankfurt-New York: Campus Verlag, 2011.

Duve, Thomas. "European Legal History - Concepts, Methods, Challenges", en: Entanglements in Legal History: Conceptual Approaches. Editado por Thomas Duve, 29-66. Frankfurt am Main, MPIeR, 2014.

Egío García, José Luis. "From Castilian to Nahuatl, or from Nahuatl to Castilian? Reflections and Doubts about Legal Translation in the Writings of Judge Alonso de Zorita (1512-1585?)". Rechtsgeschichte - Legal History $\operatorname{Rg} 24$ (2016): 122-153.

Egío García, José Luis. "Pragmatic or Heretic? Editing Catechisms in Mexico in the Age of Discoveries and Reformation (1539-1547)". En Knowledge of the Pragmatici. Legal and Moral Theological Literature and the 
Formation of Early Modern Ibero-America. Editado por Thomas Duve, Otto Danwerth, 235-274. Leiden: Brill, 2020.

Foljanty, Lena. "Legal Transfers as Processes of Cultural Translation: On the Consequences of a Metaphor", Max Planck Institute for European Legal History Research Paper Series 9 (2015): 1-18.

Friede, Juan. "La censura española del siglo XVI y los libros de historia de América", Revista de Historia de América 47 (1959): 45-94.

González Polvillo, Antonio. Análisis y repertorio de los tratados y manuales para la confesión en el mundo hispánico (ss. XV-XVIII). Huelva: Universidad de Huelva, 2009.

Grice Hutchinson, Majorlie. Early Economic Thought in Spain, 1170-1740. Londres: Allen and Unwin, 1975.

Hamilton, Alastair. "Max Weber's Protestant Ethic". En The Cambridge Companion to Weber. Editado por Stephen Turner, 151-171. Cambridge: Cambridge University Press, 2000.

Hole, Jennifer. Economic Ethics in Late Medieval England, 1300-1500. Londres: Palgrave Macmillan, 2016.

Quaglioni, Diego, Giacomo Todeschini y Gian Maria Varanini, eds. Credito e usura fra teología, diritto e amministrazione. Roma: École Française de Rome, 2005.

Lambertini, Roberto. "Economic Ethics". En The Cambridge Companion to Medieval Ethics. Editado por Thomas Williams, 306-324. Cambridge: Cambridge University Press, 2019.

Lazcano, Rafael. Fray Alonso de Veracruz (1507-1584). Misionero del saber y protector de indios. Guadarrama: Revista Agustiniana, 2007.

O’Reilly, Francisco. Duda y opinión. La conciencia moral en Soto y Medina. Pamplona: EUNSA, 2006.

Palacios, Bonifacio. "Teología Moral y sus aplicaciones, 1580-1700". En Historia de la Teología Española. Editado por Melquiades Andrés, 161179. Madrid: Fundación Universitaria Española, 1987.

Popescu, Oreste. Estudios en la Historia del Pensamiento Económico Latinoamericano. Bogotá: Plaza \& Janés, 1986.

Saranyana, José Ignacio, dir., Carmen José Alejos-Grau, coord. Teología en América Latina. Volumen II/I. Escolástica barroca, Ilustración y preparación de la Independencia (1665-1810). Madrid-Frankfurt: Iberoamericana-Vervuert, 2005.

Schüßler, Rudolf. Moral in Zweifel. Band I. Die scholastische Theorie des Entscheidens unter moralischer Unsicherheit. Paderborn: Mentis, 2003.

Schüßler, Rudolf. The debate on Probable Opinions in the Scholastic Tradition. Leiden, Boston: Brill, 2019. 
Ternus, Joseph. Zur Vorgeschichte der Moralsysteme von Vitoria bis Medina. Neue Beiträge aus gedruckten und ungedruckten Quellen, 54-61. Padeborn: Schöningh, 1930.

Tutino, Stefania. Uncertainty in post-Reformation Catholicism: a History of Probabilism. Oxford: Oxford University Press, 2018.

Vogel, David. “Business Ethics' Ethical Roots”, Business Ethics Quarterly 1, $\mathrm{n}^{\circ} 1$ (1991): 101-120.

Wren, Daniel. "Medieval or Modern? A Scholastic's View of Business Ethics, circa 1430", Journal of Business Ethics 28, nº 2 (2000): 109-119.

José Luis Egío García Instituto de Filosofía Universidad Goethe de Frankfurt Max-Planck-Institut für europäische Rechtsgeschichte Hansaallee 41 60323 Frankfurt am Main (Alemania) https://orcid.org/0000-0002-9256-8490 